\title{
Electrochemical Deposition of Conductive Superhydrophobic Zinc Oxide Thin Films
}

\author{
Mei Li, Jin Zhai, Huan Liu, Yanlin Song, Lei Jiang,* and Daoben Zhu \\ Center for Molecular Science, Institute of Chemistry, Chinese Academy of Sciences, Beijing 100080, China
}

Received: June 4, 2003; In Final Form: July 15, 2003

\begin{abstract}
A simple method of electrochemical deposition was adopted to prepare conductive hydrophobic zinc oxide $(\mathrm{ZnO})$ thin films. The surface structures were characterized by sanning electron microscopy (SEM) and atomic force microscopy (AFM). Wettability studies revealed that the surface of the as-prepared thin films showed a contact angle (CA) for water of $128.3 \pm 1.7^{\circ}$, whereas the superhydrophobic surface with a water contact angle of $152.0 \pm 2.0^{\circ}$ was obtained by (fluoroalkyl)silane modification. The superhydrophobic conductive thin films materials may have potential use such as microfluidic devices in the future. It is likely that other oxide materials may be similarly prepared by this method.
\end{abstract}

\section{Introduction}

The wettability of solid surfaces is a very important property and is governed by the chemical composition as well as the geometric structures of the surfaces ${ }^{1-3}$ A surface with water contact angle (CA) larger than $90^{\circ}$ is usually called a hydrophobic surface and that higher than $150^{\circ}$ is called a superhydrophobic surface. Conventionally, superhydrophobic surfaces can be produced mainly in two ways. One is to create a rough structure on a hydrophobic surface $\left(\mathrm{CA}>90^{\circ}\right)$, and the other is to modify a rough surface by compounds with low surface free energy, such as fluorinated or silicon compounds. ${ }^{4-7}$ Recently, we have succeeded in fabricating superhydrophobic surfaces of densely packed and honeycomb-like aligned carbon nanotubes ${ }^{8}$ and aligned polymer nanofibers ${ }^{9}$ with water contact angles larger than $150^{\circ}$. Their surfaces all show superhydrophobic characteristic properties without any chemical modification of low surface energy compounds owing to the surface aligned nanostructure. However, superhydrophobic conductive zinc oxide films with great practical and potential applications such as microfluidic devices ${ }^{10,11}$ have not been reported.

It was well-known that $\mathrm{ZnO}$ is a wide band gap semiconductor, which has been investigated as transparent conductive materials and nanostructured materials. ${ }^{12,13}$ There are some reports on the fabrication of $\mathrm{ZnO}$ thin films on a solid substrate by the reaction deposition two-step electrolysis technique, ${ }^{14}$ chemical vapor deposition, ${ }^{15}$ vapor-phase transport, ${ }^{12}$ thermal evaporation, ${ }^{13}$ self-assembly growth, ${ }^{16,17}$ epitaxial electrodeposition method, ${ }^{18}$ electrochemical reaction, ${ }^{19}$ and so on. In the present Letter, a simple method of electrochemical deposition was adopted to prepare hydrophobic conductive $\mathrm{ZnO}$ thin films; moreover, a superhydrophobic surface was obtained by (fluoroalkyl)silane modification.

\section{Experiment}

Thin films were prepared by cathodic electrodeposition from an aqueous solution composed of $1.5 \mathrm{M} \mathrm{ZnCl}_{2}$ and $1.0 \mathrm{M} \mathrm{KCl}$ kept at $22{ }^{\circ} \mathrm{C}$. ITO glass was used as the cathodic substrate after cleaning with aqueous detergent, acetone, 2-propanol, and pure water. Electrodeposition was carried out on a CHI 630A

* Corresponding author. Tel. and Fax: +86-010-82628566. E-mail: jianglei@infoc3.icas.ac.cn electrochemical analysis system (Shanghai Chenhua Inc.) with a platinum plate as the counter electrode and a SCE as a reference electrode. The thin films were then treated with a methanolic solution of hydrolyzed (heptadecafluorodecyl)trimethoxysilane $\left(\mathrm{CF}_{3}\left(\mathrm{CF}_{2}\right)_{7} \mathrm{CH}_{2} \mathrm{CH}_{2} \mathrm{Si}\left(\mathrm{OCH}_{3}\right)_{3}, 1.0 \mathrm{wt} \%\right)$ for $3 \mathrm{~h}$ and subsequently heated at $100{ }^{\circ} \mathrm{C}$ for $1 \mathrm{~h}$.

The microstructure was observed by scanning electron microscopy (JSM-6700F Field Emission, JEOL) at $3.0 \mathrm{kV}$. Surface topography of the as-prepared thin films were examined by scanning probe microscopy (SPI3800N, Seiko Instruments Inc.) in the tapping mode, and a microfabricated silicon cantilever with a bending spring constant of $1.9 \mathrm{~N} / \mathrm{m}$ and a resonance frequency of $25 \mathrm{kHz}$ was used for imaging in the air with a $100 \mu \mathrm{m}$ scanner and a scan rate of $0.50 \mathrm{~Hz}$. Conductive properties of the as-prepared thin film were examined by AFM. A commercially available conductive Si cantilever coated with $\mathrm{Au}$ was used for imaging the current signals. Prior to testing with conducting AFM, the sample was fixed on a metal plated with conductive gel to ensure an ohmic electrical contact between the sample and the sample stage on a piezo scanner. Bias voltages were applied to the thin film against the conductive cantilever.

XPS analysis of the sample was performed on a VG ESCALAB 220-IXL (VG Scientific) spectrometer. $\mathrm{Al}_{\mathrm{Ka}}$ radiation (photo energy, $1486.6 \mathrm{eV}$ ) was used, and photoelectrons were collected at a takeoff angle of $45^{\circ}$ with respect to the film surface normal. Argon ion sputtering was carried out in the same ultrahigh-vacuum chamber. The sessile drop method was used for CA measurements with a Dataphysics OCA20 contact angle system at $22{ }^{\circ} \mathrm{C}$. The water droplet size used for measurements was $5.0 \mu \mathrm{L}$. The contact angles were measured at five different points of each sample.

\section{Result and Discussion}

The chemical composition of the as-prepared thin films was measured by X-ray photoelectron spectroscopy (XPS). The concentrations of $\mathrm{Zn}, \mathrm{O}$, and $\mathrm{C}$ are 18.8, 51.5, and 29.7 atom $\%$, respectively. It indicated that the obtained films were mainly composed of zinc, oxygen, and carbon (adventitious carbon in XPS measurement process). The Auger parameter was 2009.6, which coincides with that of $\mathrm{ZnO}$. Argon ion sputtering was 

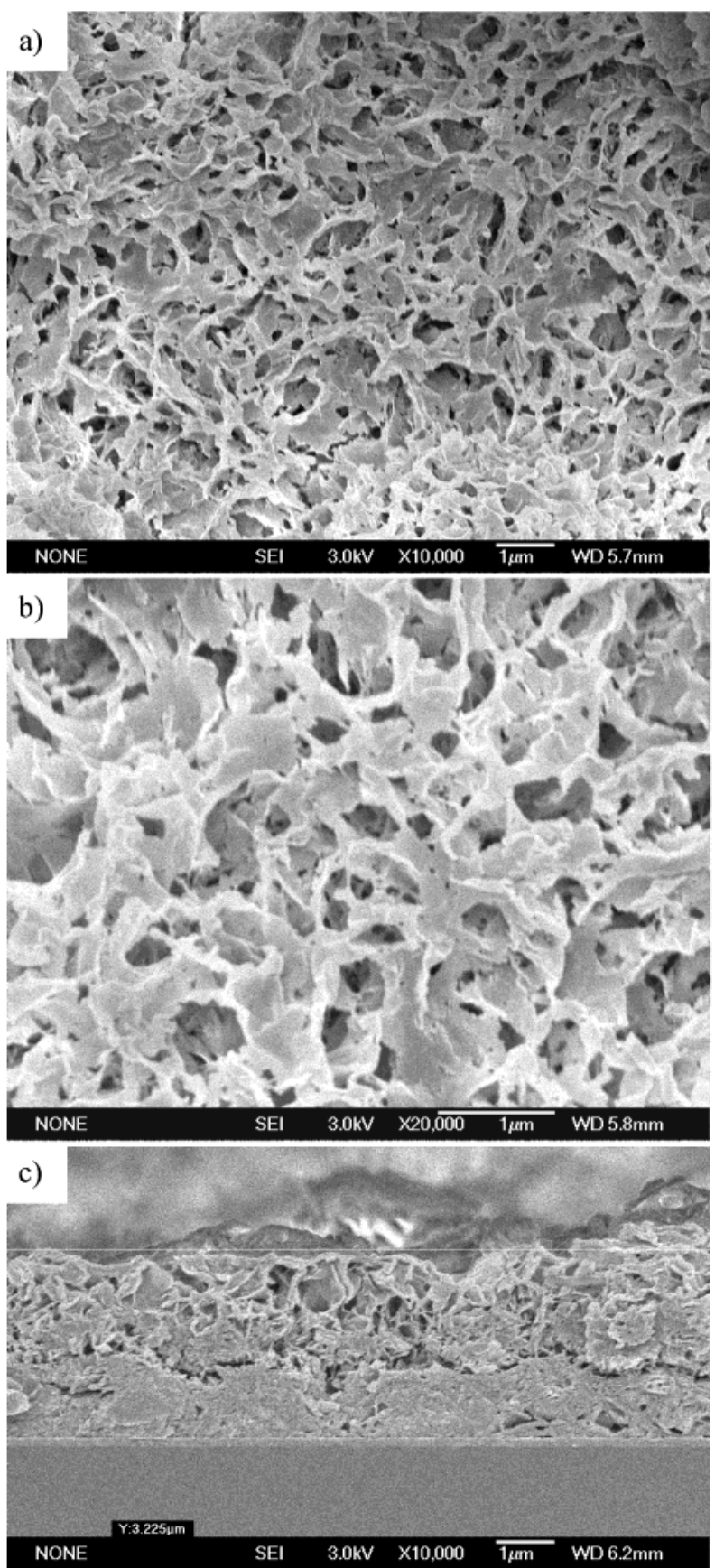

Figure 1. SEM images of as-prepared thin films prepared by electrochemical deposition: (a) overview of the as-prepared thin films surface; (b) high magnification of the overview of the as-prepared thin films surface; (c) overview of the cross section.

also used for depth profile analysis. All these results demonstrate that the surface composition of the thin films was $\mathrm{ZnO}$.

In the experiments, smooth and compact thin films can be formed by electrochemical deposition at cathodic potentials in the range -0.7 to $-1.4 \mathrm{~V}$, similar to the results of Izaki et al. ${ }^{19}$ However, relatively rough films were grown on the working electrode (ITO) when electrochemical deposition was carried out at cathodic potentials in the range -2.0 to $-3.0 \mathrm{~V}$. There are a large number of nanocrystals ${ }^{20}$ formed at cathodic potential $-3.0 \mathrm{~V}$ over $10 \mathrm{~s}$ whereas irregular porous surfaces appeared duration longer deposition times. Figure 1a is a typical scanning electron microscopy image of the as-prepared thin films on ITO. An enlarged image (Figure 1b) clearly shows that the hollow nature of porous structures with wall thicknesses of $80-270$
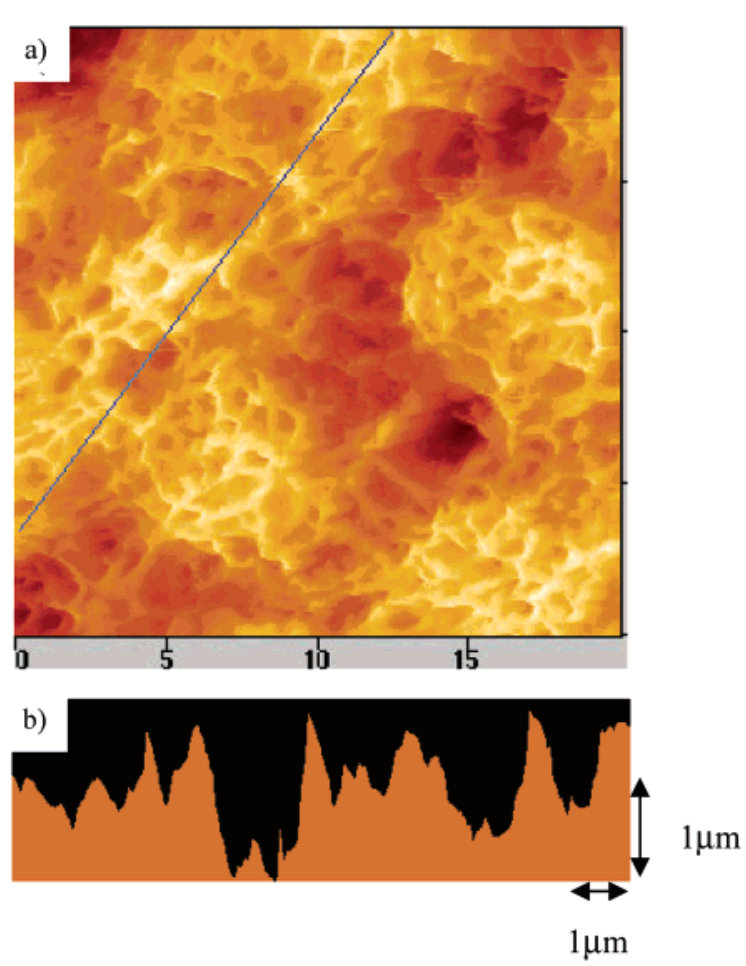

c)

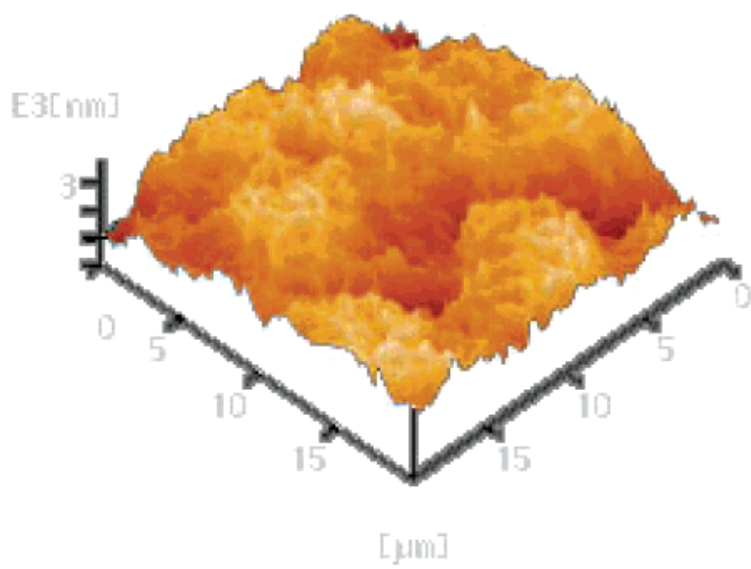

Figure 2. (a) AFM topography of a $20 \times 20 \mu \mathrm{m}^{2}$ area of the asprepared thin films. (b) Cursor profile as indicated in (a). (c) AFM 3D image of surfaces of as-prepared thin films by electrochemical deposition.

$\mathrm{nm}$ and pore diameters of $120-600 \mathrm{~nm}$. These porous structures can be explained by interpenetrating network formation, similar to electrodeposited tungsten oxide films. ${ }^{21} \mathrm{~A}$ cross section image of the thin films (Figure 1c) implies the growth process of the films. The thickness of films is about $3.0 \mu \mathrm{m}$. Near the substrate layer the films were compacted, but the surface layer was rather loose with pores. This is attributed to the overpotential of zinc deposition on ITO being fairly high. Zinc deposition is accompanied by hydrogen evolution at such negative potentials in aqueous solution. Therefore, tiny hydrogen bubbles evolved during the zinc deposition process may lead to the porosity.

The atomic force microscopy topography image (Figure 2a) was used to observe surface structures of the thin films, from which their heights are measured. The heights are in the range $800-1500 \mathrm{~nm}$. The curor profile shown as Figure 2a indicates that the surface consists of nanopores. Rough porous surface structures of the thin films were observed clearly in the AFM 

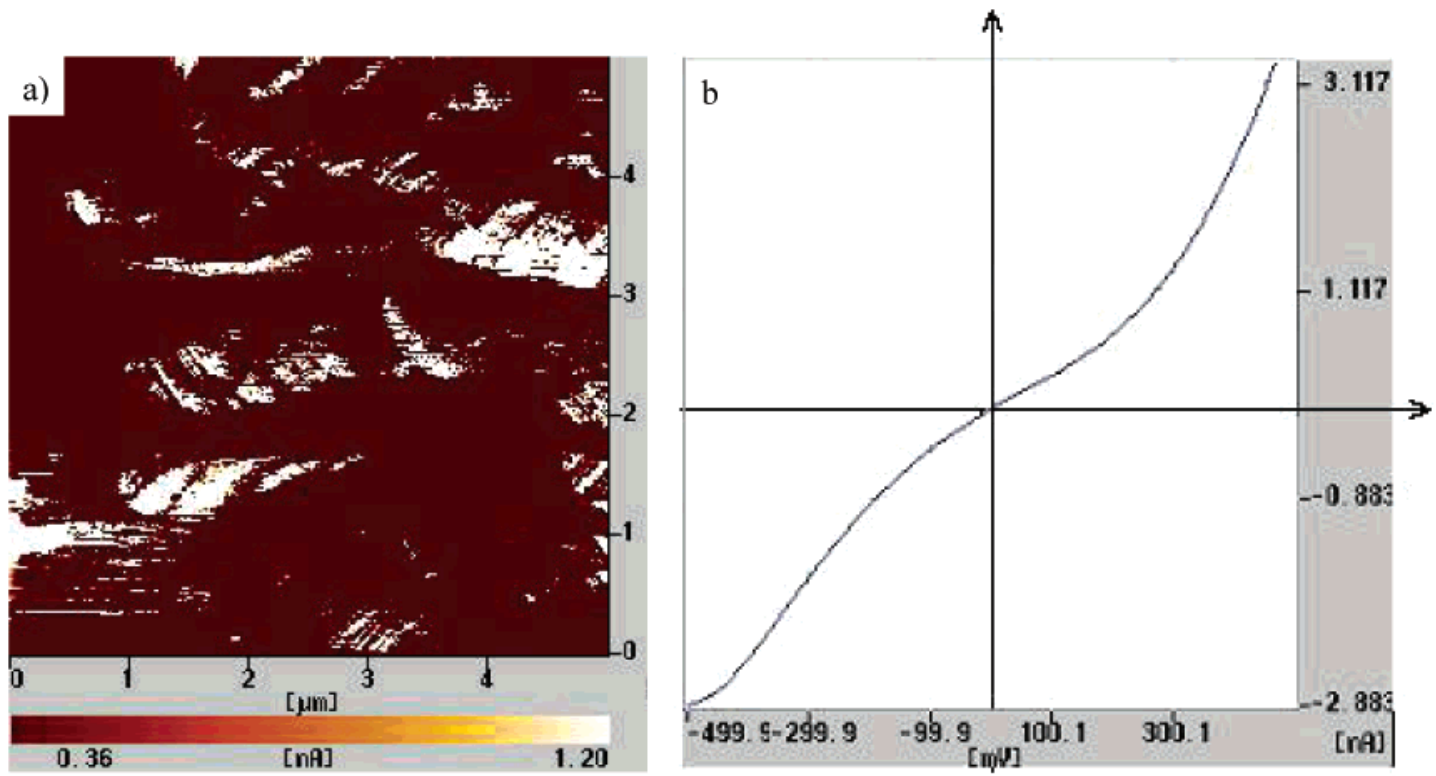

Figure 3. Conductive property measured by conducting atomic force microscopy: (a) simultaneous current scanning image of the as-prepared thin films on ITO glass at a bias voltage of $0.5 \mathrm{~V}$. (b) typical $I-V$ curve of a number of the thin films.

three-dimensional (3D) image (Figure 2c). The conductive property of the as-prepared film on ITO glass was investigated further by AFM using a conductive cantilever under application of bias voltages $22-24$ for surface complex porous structures. The current image of the as-prepared thin films at a bias voltage of $0.5 \mathrm{~V}$ was shown in Figure $3 \mathrm{a}$. The bright area in the current mapping image implies a high conductivity. A typical currentvoltage $(I-V)$ curve of a number of sites was shown in Figure 3 b. As shown, $I-V$ behavior was nearly exponential in the range of bias voltage between -0.5 and $+0.5 \mathrm{~V}$, showing semiconducting properties.

Interestingly, the as-prepared conductive $\mathrm{ZnO}$ thin film is hydrophobic with a water CA of $128.3 \pm 1.7^{\circ}$. The shape of a water droplet on the film was shown in Figure 4a. However, the water contact angle of $\mathrm{ZnO}$ thin films prepared by the spray pyrolysis method ${ }^{25}$ is $109^{\circ}$. The surfaces of the thin film are hydrophobic due to the surface with the nanoporous network structures to trap air in the nanopores. As for the approach for conducting hydrophobic materials, Mecerreyes et al. ${ }^{26}$ investigated the wettability of conducting polypyrrole (PPy) by doping with a low surface energy fluorinated counterion. The highest water contact angle of a PPy pellet with fluorinated co-dopant was $96^{\circ}$. Furthermore, the water contact angle of fabric coated with PPy with fluorinated co-dopant was $110^{\circ}$. All the data are smaller than those of the as-prepared conductive $\mathrm{ZnO}$ thin films. Therefore, the nanostructures of the as-prepared thin film surface were responsible for the hydrophobic properties. Moreover, when a low surface free energy compound such as (fluoroalkyl)silane (FAS-17) was used to modify the surface of the as-prepared thin films, the superhydrophobic surface with a CA of $152.0 \pm 2.0^{\circ}$ was obtained. The droplet shape on the thin film surface modified with FAS-17 was more spherical (Figure 4b). These results show that the surface of the as-prepared thin films is hydrophobic, because air can be trapped in the nanoporous network structures on the films surface, whereas the hydrophobicity of the thin films is remarkably improved through fluorination to show superhydrophobic characteristic properties.

In conclusion, hydrophobic conductive $\mathrm{ZnO}$ thin films were fabricated by overpotential electrochemical deposition at room temperature, and the surface modified by a (fluoroalkyl)silane a)

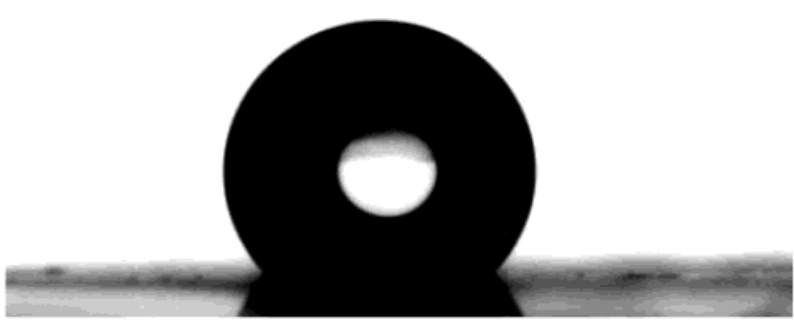

b)

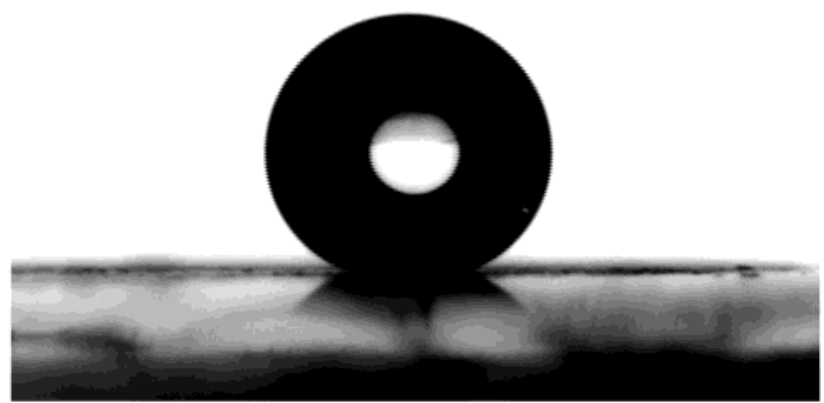

Figure 4. Shapes of water droplets on surfaces of thin films: (a) asprepared thin films by electrochemical deposition; (b) as-prepared thin films modified by FAS-17.

showed superhydrophobic properties. This fabrication method presents several advantages: (i) the thickness and morphology of films can be controlled by electrochemical parameters, (ii) relatively uniform films can be obtained on substrates with various shapes, (iii) films can be obtained on conductive substrates with low melting points below $100^{\circ} \mathrm{C}$ such as polymer, and (iv) the technique is less hazardous and more environmentally safe. ${ }^{14}$ It is likely that other oxide materials may be similarly prepared by this method.

Acknowledgment. Financial support from the State Key Project Fundamental Research (Grant 1999064504), the National Nature Science Foundation of China (29992530), and the Chinese Academy of Sciences is gratefully acknowledged. 


\section{References and Notes}

(1) (a) Gau, H.; Herminghaus, S.; Lenz, P.; Lipowsky, R. Science 1999 283, 46-49. (b) Labbortt, N.; Folkers, J. P.; Whitesides, G. M. Science 1992, 257, 1380-1382. (c) Lenz, P. Adv. Mater. 1999, 11, 1531-1534.

(2) (a) Kenneth, R. S.; Tom, E. K. Langmuir 1994, 10, 334-338. (b) Abbott, S.; Ralston, J.; Reynolds, G.; Hayes, R. Langmuir 1999, 15, 89238928. (c) Yoo, D.; Shiratori, S. S.; Rubber, M. F. Macromolecules 1998 , 31, 4309-4318. (d) Jiang, L.; Wang, R.; Yang, B.; Li, T. J.; Tryk, D. A.; Fujishima, A.; Hashimoto, K.; Zhu, D. B. Pure Appl. Chem. 2000, 72, 7377. (e) Hui, M.-H.; Blunt, M. J. J. Phys. Chem. B 2000, 104, 3833-3845.

(3) (a) Chen, W.; Fadeev, A. Y.; Hsieh, M. C.; Oner, D.; Youngblood, J.; McCarthy, T. J. Langmuir 1999, 15, 3395-3399. (b) Youngblood, J P.; McCarthy, T. J. Macromolecules 1999, 32, 6800-6806. (c) Oner, D.; McCarthy, T. J. Langmuir 2000, 16, 7777-7782.

(4) (a) Nakajima, A.; Fujishima, A.; Hashimoto, K.; Watanabe, T. Adv Mater. 1999, 11, 1365-1368. (b) Miwa, M.; Nakajima, A.; Fujishima, A. Hashimoto, K.; Watanabe, T. Langmuir 2000, 16, 5754-5760. (c) Nakajima A.; Hashimoto, K.; Watanabe, T.; Takai, K.; Yamauchi, G.; Fujishima, A. Langmuir, 2000, 16, 7044-7047.

(5) (a) Bico, J.; Marzolin, C.; Quéré, D. Europhys. Lett. 1999, 47, 220226. (b) Onda, T.; Shibuichi, S.; Satoh, N.; Tsujii, K. Langmuir 1996, 12 , 2125-2127. (c) Shibuichi, S.; Onda, T.; Satoh, N.; Tsujii, K. J. Phys. Chem. 1996, 100, 19512-19517. (d) Shibuichi, S.; Yamamoto, T.; Onda, T.; Tsujii, K. J. Colloid interface Sci. 1998, 208, 287-291. (e) Atsushi, H.; Osamu, T. Thin solid Films 1997, 303, 222-225.

(6) (a) Genzer, J.; Efimenko, K. Science 2000, 290, 2130-2133. (b) Anton, D. Adv. Mater. 1998, 10, 1197-1205.

(7) (a) Hiraki, T.; Hirotsugu, N. Langmuir 1995, 11, 136-142. (b) Nishino, T.; Meguro, M.; Nakamae, K.; Matsushita, M.; Ueda, Y. Langmuir 1999, 15, 4321-4323. (c) Thünemann, A. F. Langmuir 2000, 16, 824828. (d) Tadanaga, K.; Morinaga, J.; Matsuda, A.; Minami, T. Chem. Mater. 2000, 12, 590-592. (e) Schondelmaier, D.; Cramm, S.; Klingeler, R. Morenzin, J.; Zilkens, Ch.; Eberhardt, W. Langmuir 2002, 18, 6242-6245.

(8) (a) Li, H.; Wang, X.; Song, Y.; Liu, Y. Li, Q.; Jiang, L.; Zhu, D Angew. Chem. Int. Ed. 2001, 40, 1743-1746. (b) Li, S.; Li, H.; Wang, X.; Song, Y.; Liu, Y.; Jiang, L.; Zhu, D. J. Phys. Chem. B 2002, 106, 92749276.
(9) (a) Feng, L.; Li, S.; Li, H.; Zhai, J.; Song, Y.; Jiang, L.; Zhu, D. Angew. Chem. Int. Ed. 2002, 41, 1221-1223. (b) Feng, L.; Song, Y.; Zhai, J.; Xu, J.; Jiang, L.; Zhu, D. Angew. Chem. Int. Ed. 2003, 42, 800-802. (c) Feng, L.; Li, S.; Li, Y.; Li, H.; Zhang, L.; Zhai, J.; Song, Y.; Liu, B.; Jiang, L.; Zhu, D. Adv. Mater. 2002, 14, 1857-1860.

(10) Service, R. F. Science 1998, 282, 399-401.

(11) Meldrum, D. R.; Holl, M. R. Science 2002, 297, 1197-1198.

(12) Huang, M. H.; Wu, Y.; Feick, H.; Tran, N.; Weber, E.; Yang, P. Adv. Mater. 2001, 13, 113-116.

(13) (a) Pan, Z. W.; Dai, Z. R.; Wang, Z. L. Science 2001, 291, 19471949. (b) Dai, Y.; Zhang, Y.; Wang, Z. Solid State Commun. 2003, 126, 629-633. (c) Dai, Z. R.; Pan, Z. W.; Wang, Z. L. Adv. Funct. Mater. 2003, $13,9-24$.

(14) Masanobu, I. J. Electrochem. Soc. 1999, 146, 4517-4521.

(15) Wu, J.-J.; Liu, S.-C. Adv. Mater. 2002, 14, 215-218.

(16) Yoshida, T.; Tochimoto, M.; Schlettwein, D.; Wohrle, D.; Sugiura, T.; Minoura, H. Chem. Mater. 1999, 11, 2657-2667.

(17) Saito, N.; Haneda, H.; Sekiguchi, T.; Ohashi, N.; Sakaguchi, I.; Koumoto, K. Adv. Mater. 2002, 14, 418-421.

(18) Liu, R.; Vertegel, A. A.; Bohannan, E. W.; Sorenson, T. A.; Switzer, J. A. Chem. Mater. 13, 508-512.

(19) Izaki, M.; Omi, T. App. Phys. Lett. 1996, 68, 2439-2441

(20) This work has been prepared.

(21) Shen, P.; Chi, N.; Chan, K. Y. J. Mater. Chem. 2000, 1, 697-700.

(22) Jiang, F.; Zhang, D.; Lin, Y.; Song, Y.; Xiao, X.; Jiang, L.; Zhu D. Surf. Interface Anal. 2001, 32, 125-129.

(23) Leatherman, G.; Durantini, E. N.; Gust, D.; Moore, T. A.; Moore, A. L.; Stone, S.; Zhou, Z.; Rez, P.; Liu, Y. Z.; Lindsay, S. M. J. Phys. Chem. B 1999, 103, 4006-4010.

(24) Schneegans, O.; Moradpour, A.; Houze, F.; Angelova, A.; Henry de Villeneuve, C.; Allongue, P.; Chretien, P. J. Am. Chem. Soc. 2001, 123, $11486-11487$

(25) Sun, R. D.; Nakajima, A.; Fujishima, A.; Watanabe, T.; Hashimoto, K.; J. Phys. Chem. B 2001, 105, 1984-1990.

(26) Mecerreyes, D.; Alvaro, V.; Cantero, I.; Bengoetxea, M.; Calvo, P. A.; Grande, H.; Rodriguez, J.; Pomposo, J. A. Adv. Mater. 2002, 14, 749-752. 